\title{
CAD-FEA modeling and analysis of different full crown monolithic restorations
}

\author{
Amanda Maria de Oliveira Dal Piva ${ }^{a, *, 1}$, João Paulo Mendes Tribst ${ }^{a, 1}$, \\ Alexandre Luiz Souto Borges ${ }^{a, 1}$, Rodrigo Othávio de Assunção e Souza ${ }^{b, 1}$, \\ Marco Antonio Bottino ${ }^{a, 1}$ \\ a Department of Dental Materials and Prosthodontics, São Paulo State University (Unesp), Institute of Science and \\ Technology, Av. Eng. Francisco José Longo, no. 777, Jardim São Dimas, 12245-000, São José dos Campos, SP, Brazil \\ b Federal University of Rio Grande do Norte (UFRN), Department of Dentistry, Division of Prosthodontics, Natal, RN, \\ Brazil
}

\section{A R T I C L E I N F O}

Article history:

Received 8 January 2018

Received in revised form 9 May 2018

Accepted 7 June 2018

\section{Keywords:}

Ceramics

Finite element analysis

Monolithic crowns

Material properties

Dental materials

\begin{abstract}
A B S T R A C T
Objectives. To investigate the influence of different materials for monolithic full posterior crowns using 3D-Finite Element Analysis (FEA).

Methods. Twelve (12) 3D models of adhesively-restored teeth with different crowns according to the material and its elastic modulus were analysed: Acrylic resin, Polyetheretherketone, Composite resin, Hybrid ceramic, pressable and machinable Zirconia reinforced lithium silicate, Feldspathic, Lithium disilicate, Gold alloy, Cobalt-Chromium alloy (Co-Cr), Zirconia tetragonal partially stabilized with yttria, and Alumina. All materials were assumed to behave elastically throughout the entire deformation. Results in restoration and cementing line were obtained using maximum principal stress. In addition, maximum shear stress criteria was used for the cementing line.

Results. Restorative materials with higher elastic modulus present higher stress concentration inside the crown, mainly tensile stress on an intaglio surface. On the other hand, materials with lower elastic modulus allow stress passage for cement, increasing shear stress on this layer. Stiffer materials promote higher stress peak values.

Significance. Materials with higher elastic modulus such as $\mathrm{Co}-\mathrm{Cr}$, zirconia and alumina enable higher tensile stress concentration on the crown intaglio surface and higher shear stress on the cement layer, facilitating crown debonding.
\end{abstract}

(c) 2018 The Academy of Dental Materials. Published by Elsevier Inc. All rights reserved.

\section{Introduction}

The indication of full crowns in molars is a treatment that mainly aims to restore masticatory function due to the mag- nitude of the occlusal forces present in this region [1]. Noble metallic crowns considered as the gold standard have been widely used [2-5]. However, with the aesthetic improvement of restorative materials and the possibility of using dental ceram-

\footnotetext{
* Corresponding author at: Av. Eng. Fco. José Longo, 777, São José dos Campos, SP, 12245-000, Brazil.

E-mail addresses: amanda.piva@unesp.br (A.M.d.O. Dal Piva), joao.tribst@ict.unesp.br (J.P.M. Tribst), aleborges@ict.unesp.br (A.L.S. Borges), rodrigoothavio@gmail.com (R.O.d.A.e. Souza), mmbottino@uol.com.br (M.A. Bottino).

${ }^{1}$ Contribution: Idea, experimental design, proofread the manuscript. https://doi.org/10.1016/j.dental.2018.06.024

0109-5641/@ 2018 The Academy of Dental Materials. Published by Elsevier Inc. All rights reserved.
} 
ics instead of metals for the same indication, metallic crowns have lost their popularity. In order to minimize the occurrence of failures of the covering ceramics in both metal-ceramic crowns and full ceramic crowns $[4,6]$, ceramic materials were developed with the possibility to be used in a monolithic way. Although the main motivation for the use of ceramic crowns is to mimic an improved dental structure versus metals [7], there is no consensus on which ceramic has the best indication in the manufacture of these monolithic restorations [7-9]. For example, feldspathic or glass-ceramics may be quite successful in the anterior region [2], as well as a considerable percentage of survival up to 10 years [10]. However, when in posterior crowns, they do not present survival percentage as high as zirconia crowns $[4,5]$.

Toughness consists in a property of the materials defined by the amount of plastic and elastic deformation energy required to fracture a material. The fracture toughness corresponds to the energy required to propagate critical defects in a structure, directly related to the stress/strain curve [11]. Manufacturers' caution regarding the material indication exists since all ceramic materials have adequate toughness to withstand the masticatory loads; however, they can fail, therefore, a tough material is generally resistant but, a resistant material is not always tough [11]. The presence of humidity, temperature and continuous incidence of mastication with $\mathrm{pH}$ variations make the oral medium an arduous survival environment, causing even the most resistant materials to be degraded in the long term $[12,13]$. In this sense, noble metals are still a restorative alternative due to their ductility and absence of oxidation in the oral environment. Thus, toughness does not seem to be the only factor responsible for the longevity of the restoration, as ceramics are as close to the metals or even higher in flexural strength. Therefore, materials with a different composition proposal have come to draw the attention of dentists, because perhaps a material that is not as resistant as zirconia could respond better to the masticatory loads and thus adapt and survive. With this intention, polymer infiltrated ceramics with a resin matrix were developed. This polymer infiltration could be able to absorb chewing and be a better option in the long term [8]. There are many materials with distinct characteristics that share the indication of rehabilitating posterior full crowns, from resins in the manufacture of temporary restorations to highly resistant ceramics. Thus, the possibility of using materials with elastic modulus from $2 \mathrm{GPa}$ to a ceramic with a 100 times greater elastic modulus raises the question of how these restorations behave mechanically. Understanding the mechanical behavior of restorations and if this mechanism can be based on the restorative material choice is not clear and is not part of the daily routine of the dentist. This is because an extremely tough material can be used with the guarantee of the crown's structural durability; moreover, a brittle material can be chosen to dampen the masticatory loads. These materials share the possibility of being used in the same indication with the same anatomy onto a standard dental preparation and often being cemented in a similar way, making the restorative procedure routine for whichever material is the dentist's choice. However, can the material's behavior during function influence the longevity of the treatment? The objective of this study was to evaluate the stress regions of the restoration and the

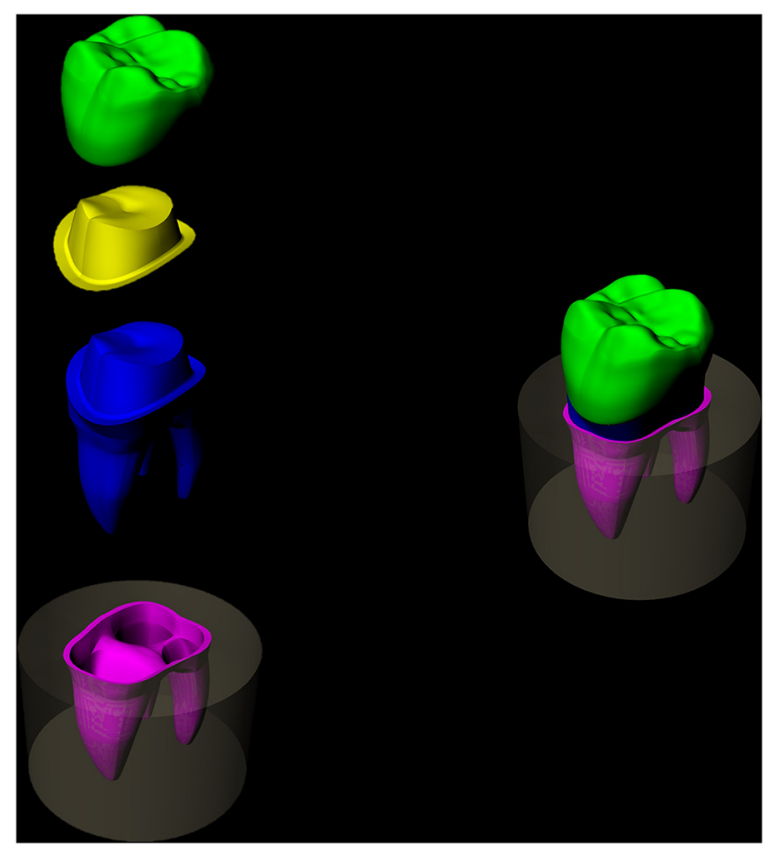

Fig. 1 - 3D FEA model of a tooth: (a) monolithic crown; (b) cementing line; (c) tooth remnant; (d) periodontal ligament; (e) restored tooth.

cementing line according to the restorative material used (12 levels) in posterior monolithic total crowns using non-linear 3D finite element analysis. The alternative hypothesis was that there would be no difference on the stress distribution in the restorations and cementing line, regardless of the material used.

\section{Materials and methods}

\subsection{Finite element analysis (FEA) pre-processing}

A human molar model was created using modeling software (Rhinoceros version 5.0 SR8, McNeel North America, Seattle, WA, USA). For this, anatomical lines referring to the occlusal grooves and surrounding crown bases were constructed so that each face was obtained following anatomical conditions. After creation of the surfaces, they were fixed to form a volumetric solid of a first maxillary molar. Next, the crown was separated from the root and a total crown preparation was constructed with $5.5 \mathrm{~mm}$ of height and $12^{\circ}$ of occlusal convergence in the axial walls.

The external layer of the dental preparation was subsequently duplicated and used as a base for making the cementing line with $0.1 \mathrm{~mm}$ of thickness. This allows all the contacting faces of the preparation and the cement to be the same in number and shape and thus reduce the interference during the mathematical analysis. The external surface of the cement was used as a base for the inner surface of the crown. The final geometries were: monolithic crown, cement line, dental preparation, periodontal ligament and fixation cylinder (Fig. 1). All bodies were considered volumetric solids. 


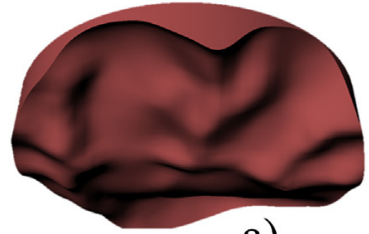

a)

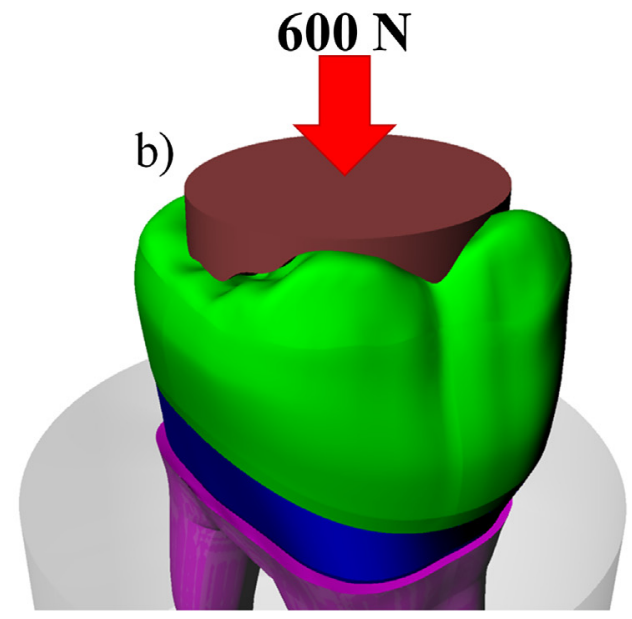

Fig. 2 - Food modeling and load application: (a) bolus on the occlusal surface; (b) occlusal load.

Table 1 - Mechanical properties of materials and structures used in this study.

\begin{tabular}{lll} 
Material/structure & $\begin{array}{l}\text { Young's } \\
\text { modulus (GPa) }\end{array}$ & $\begin{array}{l}\text { Poisson's } \\
\text { ratio }\end{array}$ \\
\hline Enamel [14] & 84.1 & 0.33 \\
Dentin [15] & 18.6 & 0.32 \\
Food bolus [16] & $3.41\left(\times 10^{-3}\right)$ & 0.10 \\
Alumina [17] & 314 & 0.22 \\
Zirconia [18] & 200 & 0.31 \\
Lithium disilicate [19] & 95 & 0.25 \\
Poliuretano [20] & 3.6 & 0.3 \\
Composite resin [21] & 11 & 0.28 \\
Hybrid ceramic [22] & 34.7 & 0.28 \\
Pressable ZLS [23] & 70 & 0.23 \\
Feldspar [22] & 48.7 & 0.23 \\
PEEK [24] & 3.70 & 0.40 \\
Gold alloy [25] & 91 & 0.32 \\
CoCr alloy [26] & 220 & 0.30 \\
Acrilic resin [27] & 2.7 & 0.35 \\
Usinable ZLS [23] & 70 & 0.23 \\
Periodontal ligament [16] & $0.15\left(\times 10^{-3}\right)$ & 0.45 \\
Resinous cement [28,29] & 7.5 & 0.3 \\
\hline
\end{tabular}

\subsection{FEA solution}

\subsubsection{Mesh generation}

The geometries were imported into ANSYS software CAE (ANSYS 17.2, ANSYS Inc., Houston, TX, USA) in STEP format and tetrahedral elements formed the mesh. A convergence test of $10 \%$ mesh control determined the mean number of 95,263 elements and 169,672 nodes.

\subsubsection{FEA processing}

The materials and structures properties were attributed to each solid component with isotropic, homogeneous and linearly elastic behavior. Young's modulus and Poisson's ratio were reported (Table 1) [14-29] and all contacts were ideally cast.

\subsubsection{Loading and fixations}

Load application $(600 \mathrm{~N})$ occurred similar to the methodology by Ausielo et al. [16] which considered the contact between food bolus and tooth surface during the closing phase of the chewing cycle (Fig. 2). A cylinder base was selected for the system fixation condition, ensuring only the movement constraint on the $\mathrm{Z}$ axis so that the deformation generated in all directions could be computed.

\subsection{FEA pos-processing}

In order to evaluate the stress distribution generated by masticatory loads in the restored teeth, finite element analysis (FEA) has been used due to specimen standardization, low cost, and because it is a numerical method that offers a means to find an approximate solution [16,30-32]. Some terms are very common when this computational method is used such as stress and stress concentration. Stress consists of the response of the atoms and molecules to a load applied in the evaluated structure [11]. Herein, results in restoration and cementing line were obtained using maximum principal stress (tensile stress results in $\mathrm{MPa}$ ). In addition, maximum shear stress criteria was used for the cementing line.

Stress concentration is defined as a ratio of peak stress to nominal/average stress in the concerned region [33]. Thus, the stress concentration (SC) in the crown intaglio surface and on the cementing line were calculated according to the formula: $S C=\frac{S p}{a S}$, where, "Sp" corresponds to the stress peak value and $\mathrm{aS}$, to the average stress values in the concerned regions, in $\mathrm{MPa}$. Strength property consists in the necessary force to fracture a structure with known area [34]. Thus, the failure risk (Fr) of the restoration and cementing line were calculated according to the formula: $\mathrm{Fr}=\frac{\mathrm{Sp}}{\text { Strength }}$. The restoration failure risk consisted on the material highest peak divided per its tensile strength. For the cementing line, its cohesive failure risk was evaluated by the stress peak to tensile strength ratio and the adhesive failure risk, was calculated by the stress peak to the bond strength to dentin ratio.

\section{Results}

The results generated in maximum principal stress show the tensile stress pattern generated in three regions of the pros- 


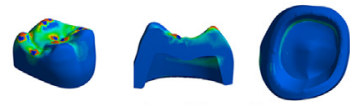

Acryilic resin

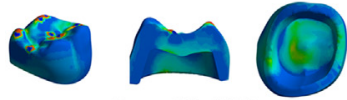

Pressable ZLS
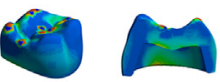

Gold alloy
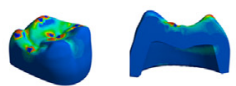

PEEK
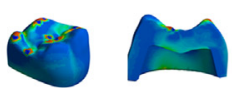

Usinable ZLS
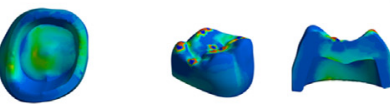

Feldspathic
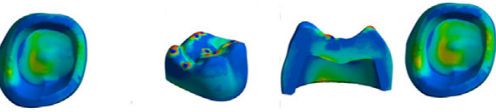

Lithium disilicate

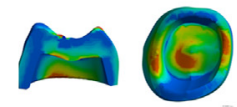

Co-Cr alloy
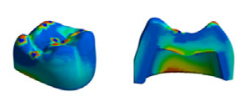

YTZP
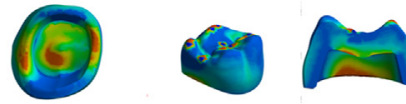

Alumina

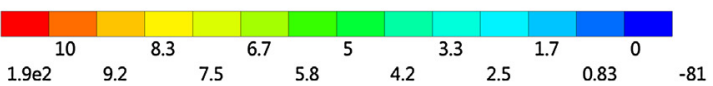

Fig. 3 - Stress generated in monolithic crowns; (a) acrylic resin, (b) PEEK, (c) composite resin, (d) hybrid ceramic, (e) pressable ZLS, (f) ZLS CAD, (g) feldspathic, (h) lithium disilicate, (i) gold alloy, (j) CoCr alloy, (k) YTZP and (l) alumina.

thetic crown (occlusal face, sagittal cut and internal surface) through a stress map (Fig. 3). The stress distribution in the restoration was impaired directly proportional to the elastic modulus of the restorative material. Considering the stresses generated in the perspective cementing line (Fig. 4), the stress distribution was improved with the increase of elastic modulus of the restorative material used in the crown for tensile and shear criteria's. By isolating the inner region of the crown, it is possible to observe that the higher the elastic modulus of the restorative material, the higher the tensile stress peak values (Fig. 5). The same behavior was observed for maximum shear stress on cement layer, with few areas of higher stress (Fig. 4), but higher peaks of shear stress (Fig. 5). Stress concentration results are summarized in Table 2 [17,35-40]. This finding suggests that the higher the stress concentration ratio the best is the stress distribution. This fact can be justified because the peak will never be equal to the average value. Therefore, a notable difference between stress peak and average stress values will result in values greater than 1 . Thus, acrylic resin showed the best stress concentration for the crown (7.14). For the cementing line, the best behavior was found for the alumina crown (3.33), followed by zirconia and CoCr alloy (3.22). Considering the crown failure risk, hybrid ceramic showed the lowest risk (0.01) while alumina (0.06) showed the highest. For the cementing line, all materials showed proportionally $( \pm 40 \%)$ higher cohesive failure risk $(0.15-0.21)$ in comparison

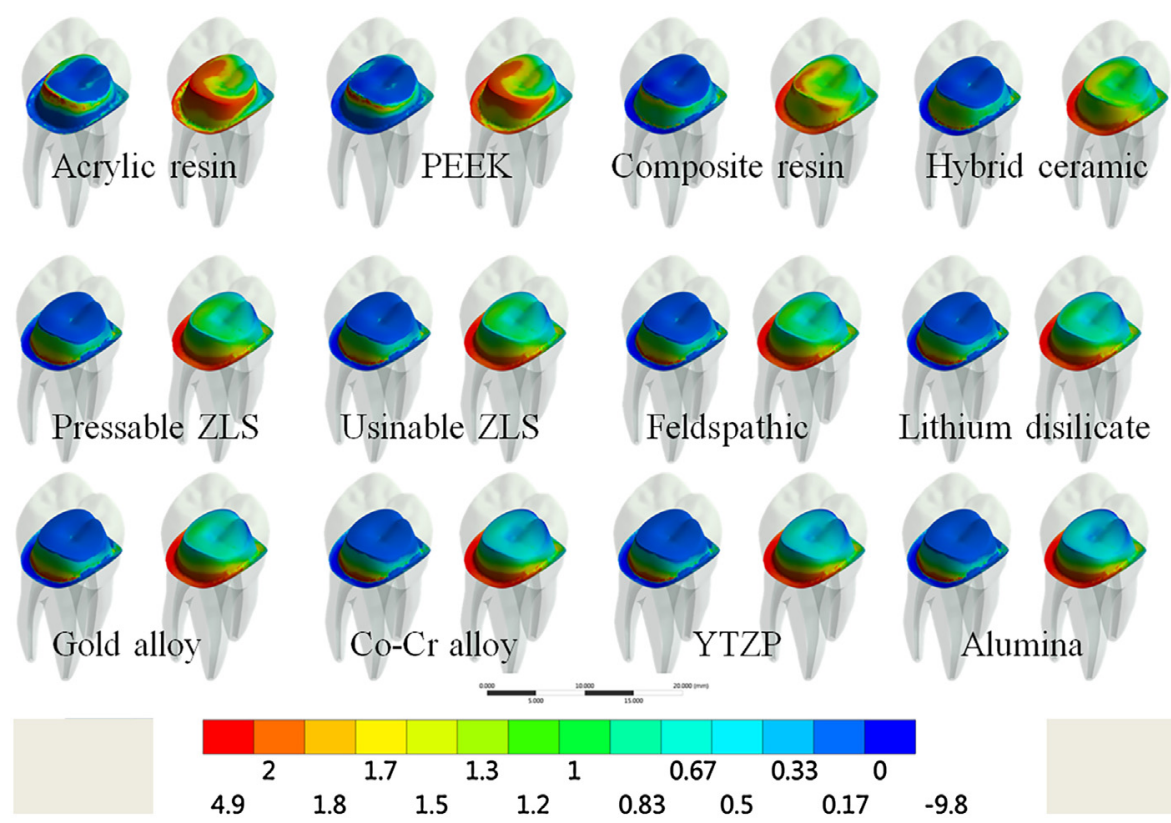

Fig. 4 - Tensile and shear stresses generate on cementing line according to the monolithic crowns, respectively: (a) acrylic resin, (b) PEEK, (c) composite resin, (d) hybrid ceramic, (e) pressable ZLS, (f) ZLS CAD, (g) feldspathic, (h) lithium disilicate, (i) gold alloy, (j) CoCr alloy, (k) YTZP and (l) alumina. 


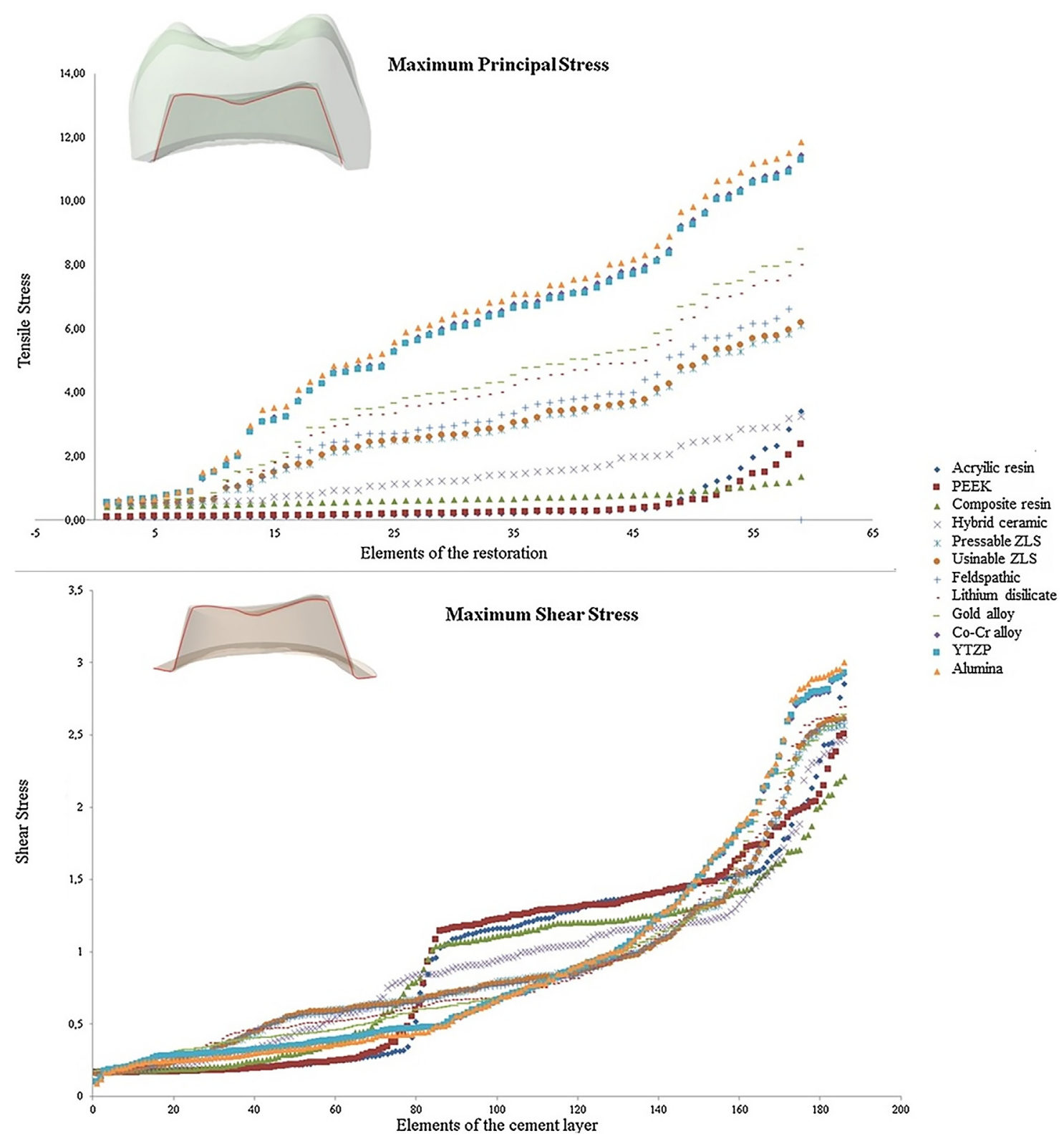

Fig. 5 - Maximum principal stress (MPa) distribution along the crown internal surface and Maximum shear stress (MPa) distribution along the cementing layer external surface.

to adhesive failure risk (0.06-0.09), with the worst performance for the alumina crown and the best performance for the composite resin crown.

\section{Discussion}

The purpose of this study was to evaluate the stressed regions in the posterior monolithic crown and in the cementing line according to the restorative material. The results demonstrated that there is a significant difference between the biomechanical behavior as a function of the material used in the monolithic restoration, rejecting the alternative hypothesis. This study revealed that the observed values in the colorimetric stress scale of the crowns were considerably lower than the values of the critical stress of the materials used to build the crowns. Thus, it is suggested that there will be no fracture occurrence during occlusion. These results may be supported by similar findings in the literature for such materials $[7,8,41]$

For posterior monolithic crowns, different classes of materials may be used such as: acrylic resin generally used for temporary prosthesis; Polyetheretherketone (PEEK) polymer is an alternative resilient material [42], a hybrid ceramic that emerged with the objective of associating the composite resin and feldspathic ceramic qualities; zirconia reinforced lithium silicate, a material structurally similar to lithium disilicate reinforced with zirconia particles $[22,43,44]$; lithium disilicate [45]; noble metal alloys; yttria-tetragonal zirconia polycrystal (YTZP); and alumina-based ceramics are some possible treatment examples to be found in an oral environment. The higher 
Table 2 - Tensile strength of the materials simulated in this study, stress peak, average stress, stress concentration ratio and failure risks for crown and cementing line.

\begin{tabular}{|c|c|c|c|c|c|c|c|c|c|c|}
\hline \multirow[t]{2}{*}{ Material } & \multicolumn{4}{|c|}{ Crown } & \multicolumn{4}{|c|}{ Resin cement } & \multicolumn{2}{|c|}{ Failure risk } \\
\hline & $\begin{array}{l}\text { Tensile } \\
\text { strength }\end{array}$ & $\begin{array}{l}\text { Stress } \\
\text { peak }\end{array}$ & $\begin{array}{l}\text { Average } \\
\text { stress }\end{array}$ & SC & $\begin{array}{l}\text { Failure } \\
\text { risk }\end{array}$ & $\begin{array}{l}\text { Stress } \\
\text { peak }\end{array}$ & $\begin{array}{l}\text { Average } \\
\text { stress }\end{array}$ & SC & Cohesive & Adhesive \\
\hline Alumina [17] & 193 & 11.86 & 6.02 & 1.97 & 0.06 & 3 & 0.91 & 3.3 & 0.21 & 0.09 \\
\hline CoCr alloy [35] & 680 & 11.44 & 5.75 & 1.99 & 0.02 & 2.92 & 0.91 & 3.22 & 0.20 & 0.08 \\
\hline Zirconia [36] & 745 & 11.28 & 5.66 & 1.99 & 0.02 & 2.93 & 0.91 & 3.22 & 0.20 & 0.09 \\
\hline Lithium disilicate $^{\mathrm{a}}$ & $173 \pm 9$ & 7.99 & 3.76 & 2.13 & 0.05 & 2.69 & 0.9 & 3 & 0.19 & 0.08 \\
\hline Gold alloy [37] & 462 & 8.48 & 4.01 & 2.11 & 0.02 & 2.64 & 0.88 & 2.99 & 0.18 & 0.08 \\
\hline Pressable ZLS ${ }^{a}$ & $180 \pm 11$ & 6.1 & 2.76 & 2.21 & 0.03 & 2.56 & 0.89 & 2.87 & 0.18 & 0.07 \\
\hline Usinable ZLS ${ }^{\mathrm{a}}$ & $159 \pm 18$ & 6.18 & 2.83 & 2.18 & 0.04 & 2.61 & 0.89 & 2.93 & 0.18 & 0.08 \\
\hline Feldspathic $^{\mathrm{a}}$ & $123 \pm 7$ & 6.62 & 3.05 & 2.17 & 0.05 & 2.6 & 0.89 & 2.91 & 0.18 & 0.08 \\
\hline Hybrid ceramic ${ }^{a}$ & $227 \pm 23$ & 3.26 & 1.42 & 2.29 & 0.01 & 2.46 & 0.89 & 2.76 & 0.17 & 0.07 \\
\hline Composite resin [38] & 45 & 1.35 & 0.68 & 1.98 & 0.03 & 2.21 & 0.89 & 2.49 & 0.15 & 0.06 \\
\hline PEEK [39] & 54 & 2.38 & 0.4 & 5.91 & 0.04 & 2.5 & 0.94 & 2.67 & 0.17 & 0.07 \\
\hline Acrylic resin [40] & 79 & 3.41 & 0.48 & 7.14 & 0.04 & 2.85 & 0.92 & 3.09 & 0.20 & 0.08 \\
\hline
\end{tabular}

${ }^{a}$ The tensile strength values were obtained by the authors following Della Bona et al. [38] methodology.

stress peaks in the crowns were observed in the materials with higher elastic modulus corroborating with previous studies $[9,19]$. Considering the observed stress peaks and although it does not show a risk of fracture for the materials, it can be harmful when located in the lower portion of the total crowns since this region lies in addition to the layer of resinous cement and a detachment of the prosthetic piece could be initiated in these stressed regions. This assertion is mainly of concern for YTZP, which in addition to having high elastic modulus presents poor adhesive properties [46], suggesting a worse prognosis. Case reports have already been documented in the literature $[12,47]$, supporting this theory. Still evaluating the stresses in the crowns in a sagittal section, it is possible to observe a tensile zone present on the intaglio surface of the crowns, validating our model since it is in this region that the propagation of crack in brittle materials begins [48,49], justifying the results obtained in the restoration intaglio surface. Brittle materials have low fracture toughness, whereas materials that undergo plastic deformation such as metals present higher levels of fracture toughness, but also fail due to tensile forces [50,51]. In this study, it was observed that the $\mathrm{Cr}-\mathrm{Co}$ alloy concentrated more stress than the gold alloy and acted similarly to the ceramics of larger elastic modulus.

A previous study that evaluated total crowns on different substrates found that nanoceramic resin crowns with an elastic modulus of $12 \mathrm{GPa}$ are more likely to fatigue the cementing line than lithium disilicate crowns. Such an inference is similar to the present results. However, the authors did not simulate a cement layer and reported that the stress at the interface may have occurred due to the difference between the elastic modulus of the restorative material and the substrate [50]. This explanation of the difference in elastic modulus does not seem to be responsible for the stress accumulation in the intermediate material (cement layer). Only when the restorative material was the hybrid ceramic and composite resin whose elastic modulus is similar to dentin did it reduce the difference in the rigidity between crown and tooth, and no mechanical benefit was obtained for the cement. Herein, these materials and also PEEK showed the lowest cement cohesive failure risk, which corresponds to the best mechanical benefit for the cement. Several FEA investigations that studied total crowns and the influence of restorative materials simplify the cementing line by using perfectly bonded contacts between the structures and consider that an ideal cementation has occurred $[9,50,51]$. Although this simplifying this method is possible, facilitates processing and speeds up the analysis for the crown, inferences on detachment and cohesive failure of the cement should be performed in situations where the cement has been simulated as an individual structure because the presence of the cement can modify the system mechanical behavior $[41,52,53]$, as seen in the results herein.

The cementing layer was modeled with a thickness of $100 \mu \mathrm{m}$, according to the literature [54,55]. This layer is relevant for studies since cohesive failures on this layer can occur in the long term [56], and thus allow restoration displacement. The results herein corroborates with this sentence since cohesive cementing line failure risk was superior than adhesive failure to dentin, regardless the crown material (Table 2). Referring to Fig. 4 , it is possible to note that the more rigid the crown, the less tensile stress reaches the cement, as this crown was able to concentrate the stress itself. This behavior suggests that the group restored with crown with higher elastic modulus minimizes damage in the cement layer; however, they increase the both evaluated cement failure risks. Nevertheless, when correct cementation is done, the cement line is minimal, which means that the differences between the groups are few, even though they are significant. According to the colored graphs, the difference of at most $2 \mathrm{MPa}$ makes it impossible to predict if the groups would clinically present very different behavior that could promote cement fracture. But, using the formula to calculate the failure risk, it was possible to suggest that alumina crowns showed the higher failure risk for the cement. Despite this limitation, the ability of materials with low elastic modulus to allow the passage of stress to the cement is noticeable, and therefore careful cementation should always be indicated, since in these cases the cement will be more stressed and could compromise the mechanics of the restoration and its longevity when in larger thicknesses. 
In this paper higher stress peak was proportional to the higher possibility of failure. However, it is important to notice that it is not a rule. Thus, stress peak and also average values should be always evaluated. Here, the highest stress peak and the highest failure risk were found for the crown in alumina. As reported in the literature, failures involving monolithic crowns are related to the cementing layer, thus, cohesive and adhesive failure risks were evaluated for this layer. As the same cement was simulated in all conditions, its tensile strength [57] and bond strength to dentin [58] available in the literature were used. This demonstrates that the failure criteria of the adhesive layer's integrity can be directly connected with the shear action of the surrounding axial walls. Thus, these results support the importance of evaluating the adhesive resistance in tests that evaluate this type of resultant stress. The generated tensile stress on the total crowns appears to be inversely proportional to the cement layer, but the higher peaks of shear stress were present when rigid crowns were used. Basically, the loss of total crown adhesion seems to be related to the extremes of the simulated groups. Therefore, crowns with high elastic modulus exhibit their internal surface traction from the resin cement, and crowns with low elastic modulus allow more areas of shear stress in the same cementing layer. In order to promote more durable adhesion and to maintain the total crown in position, a topographic modification by chemical or physical agents of the inner face of the crown increases the adhesive resistance between the crown and cement, which makes the shear stress insufficient to overcome the adhesive strength obtained after surface treatment as the elastic modulus of the crown is still the same, yet it is assumed that the stress still exists of such magnitude.

The crown in acrylic resin is used in dentistry as a temporary restoration and although it allows the cement to concentrate tensile and shear stresses, its indication is very concise and the practicality of making restorations makes this material practical for use in several cases. However, PEEK is a relatively new material in dentistry and is handled by the CAD/CAM machining process [59]. Although it is indicated for crowns or infrastructures [59], its elastic modulus is low compared to most of the materials available with the same indication, and its mechanical behavior when used as a total crown is close to the mechanical behavior of the acrylic resin in the analysis of the generated stresses, but, with lower cement failure risk. The crowns in composite resin and hybrid ceramic demonstrate an elastic modulus that approaches the dentin structure and the resin cement, and although they are not capable of reducing tensile stresses in the cementing line as much as a zirconia crown, they are capable of not concentrating tensile stress on its inner face, thus suggesting interesting survival since these regions are the first regions to fail in a total crown $[16,60]$. Hybrid ceramic presented the lowest failure risk for the crown and for the cement line. For the correct decision-making in selection of the materials for patients other properties should be considered such as wear resistance, degradation, fatigue resistance, toughness, aesthetics. Therefore, hybrid ceramic monolithic crown showed the best mechanical behavior being suggested as the best monolithic crown for posterior region.

\section{Conclusion}

Within the limitations of this study it is possible to conclude that the hybrid ceramic showed more promising mechanical behavior results for posterior monolithic crown with lower failure risks.

\section{Acknowledgement}

The authors thank the support from São Paulo Research Foundation (FAPESP) through the scholarship support (\#2017/11535-3) that enabled the development of this paper.

\section{REF E R E N C E S}

[1] Neill DJ, Kydd WL, Nairn RI. Functional loading of the dentition during mastication. J Prosthet Dent 1989;62:218-28.

[2] Anusavice KJ. Standardizing failure, success, and survival decisions in clinical studies of ceramic and metal-ceramic fixed dental prostheses. Dent Mater 2012;28:102-11, http://dx.doi.org/10.1016/j.dental.2011.09.012.

[3] Larsson C, Wennerberg A. The clinical success of zirconia-based crowns: a systematic review. Int J Prosthodont 2014;27:33-43.

[4] Sailer I, Makarov NA, Thoma DS, Zwahlen M, Pjetursson BE. All-ceramic or metal-ceramic tooth-supported fixed dental prostheses (FDPs)? A systematic review of the survival and complication rates. Part I: single crowns (SCs). Dent Mater 2015;31:603-23.

[5] Pjetursson BE, Sailer I, Makarov NA, Zwahlen M, Thoma DS. All-ceramic or metal-ceramic tooth-supported fixed dental prostheses (FDPs)? A systematic review of the survival and complication rates. Part II: multiple-unit FDPs. Dent Mater 2015;31:624-39

[6] Araújo NS, Moda MD, Silva EA, Zavanelli AC, Mazaro JV, Pellizzer EP. Survival of all-ceramic restorations after a minimum follow-up of five years: a systematic review. Quintessence Int 2016;47:395-405.

[7] Seydler B, Rues S, Müller D, Schmitter M. In vitro fracture load of monolithic lithium disilicate ceramic molar crowns with different wall thicknesses. Clin Oral Investig 2014;18:1165-71, http://dx.doi.org/10.1007/s00784-013-1062-8.

[8] El Zhawi H, Kaizer MR, Chughtai A, Moraes RR, Zhang Y. Polymer infiltrated ceramic network structures for resistance to fatigue fracture and wear. Dent Mater 2016;32:1352-61, http://dx.doi.org/10.1016/j.dental.2016.08.216.

[9] de Kok P, Kleverlaan CJ, de Jager N, Kuijs R, Feilzer AJ. Mechanical performance of implant-supported posterior crowns. J Prosthet Dent 2015;114:59-66.

[10] Morimoto S, Rebello de Sampaio FB, Braga MM, Sesma N, Özcan M. Survival rate of resin and ceramic inlays, onlays, and overlays: a systematic review and meta-analysis. J Dent Res 2016;95:985-94.

[11] Anusavice JL, Shen C, Rawls HR. Philips materiais dentários. 12th ed. Rio de Janeiro: Elsevier; 2013.

[12] Tartaglia GM, Sidoti E, Sforza C. A 3-year follow-up study of all-ceramic single and multiple crowns performed in a private practice: a prospective case series. Clinics 2011;66:2063-70, http://dx.doi.org/10.1590/S1807-59322011001200011. 
[13] Addison O, Fleming GJ, Marquis PM. The effect of thermocycling on the strength of porcelain laminate veneer materials. Dent Mater 2003;19:291-7.

[14] Roscoe MG, Noritomi PY, Novais VR, Soares CJ. Influence of alveolar bone loss, post type, and ferrule presence on the biomechanical behavior of endodontically treated maxillary canines: strain measurement and stress distribution. J Prosthet Dent 2013;110:116-26.

[15] Soares CJ, Raposo LH, Soares PV, Santos-Filho PC, Menezes MS, Soares PB, et al. Effect of different cements on the biomechanical behavior of teeth restored with cast dowel-and-cores-in vitro and FEA analysis. J Prosthodont 2010;19:130-7.

[16] Ausiello P, Ciaramella S, Martorelli M, Lanzotti A, Zarone F, Watts DC, et al. Mechanical behavior of endodontically restored canine teeth: effects of ferrule, post material and shape. Dent Mater 2017;33:1466-72, http://dx.doi.org/10.1016/j.dental.2017.10.009.

[17] Dong X, Shin YC. Multiscale finite element modeling of alumina ceramics undergoing laser-assisted machining. J Manuf Sci Eng 2016;138, http://dx.doi.org/10.1115/1.4029858. V002T02A089- V002T02A099.

[18] Çaglar A, Bal BT, Karakoca S, Aydın C, Yllmaz H, Sarnsoy S. Three-dimensional finite element analysis of titanium and yttrium-stabilized zirconium dioxide abutments and implants. Int J Oral Maxillofac Implants 2011;26:961-9.

[19] Ma L, Guess PC, Zhang Y. Load-bearing properties of minimal-invasive monolithic lithium disilicate and zirconia occlusal onlays: finite element and theoretical analyses. Dent Mater 2013;29:742-51.

[20] Souza A, Xavier TA, Platt JA, Borges A. Effect of base and inlay restorative material on the stress distribution and fracture resistance of weakened premolars. Oper Dent 2015;40:E158-66, http://dx.doi.org/10.2341/14-229-L.

[21] Srirekha A, Bashetty K. A comparative analysis of restorative materials used in abfraction lesions in tooth with and without occlusal restoration: three-dimensional finite element analysis. J Conserv Dent 2013;16:157-61.

[22] Ramos Nde C, Campos TM, Paz IS, Machado JP, Bottino MA, Cesar PF. Microstructure characterization and SCG of newly engineered dental ceramics. Dent Mater 2016;32:870-8, http://dx.doi.org/10.1016/j.dental.2016.03.018.

[23] Zimmermann M, Egli G, Zaruba M, Mehl A. Influence of material thickness on fractural strength of CAD/CAM fabricated ceramic crowns. Dent Mater J 2017;36:778-83, http://dx.doi.org/10.4012/dmj.2016-296.

[24] Anguiano-Sanchez J, Martinez-Romero O, Siller HR, Diaz-Elizondo JA, Flores-Villalba E, Rodriguez CA. Influence of PEEK coating on hip implant stress shielding: $s$ finite element analysis. Comput Math Methods Med 2016;2016:6183679, http://dx.doi.org/10.1155/2016/6183679.

[25] Shinya A, Yokoyama D, Lassila LV, Shinya A, Vallittu PK. Three-dimensional finite element analysis of metal and FRC adhesive fixed dental prostheses. J Adhes Dent 2008;10:365-71

[26] Kayabaşı Oğuz, Yüzbasıoğlu Emir, Erzincanlı Fehmi. Static, dynamic and fatigue behaviors of dental implant using finite element method. Adv Eng Softw 2006;37:649-58.

[27] Nagai E, Otani K, Satoh Y, Suzuki S. Repair of denture base resin using woven metal and glass fiber: effect of methylene chloride pretreatment. J Prosthet Dent 2001;85:496-500.

[28] Nakamura T, Wakabayashi K, Kinuta S, Nishida H, Miyamae M, Yatani H. Mechanical properties of new self-adhesive resin-based cement. J Prosthodont Res 2010;54:59-64.

[29] Jongsma LA, de Jager N, Kleverlaan CJ, Pallav P, Feilzer AJ. Shear bond strength of three dual-cured resin cements to dentin analyzed by finite element analysis. Dent Mater 2012;28:1080-8.
[30] Dal Piva AMO, Tribst JPM, Souza ROAE, Borges ALS. Influence of alveolar bone loss and cement layer thickness on the biomechanical behavior of endodontically treated maxillary incisors: a 3-dimensional finite element analysis. J Endod 2017;43:791-5.

[31] Monteiro JB, Dal Piva AMO, Tribst JPM, Borges ALS, Tango RN The effect of resection angle on stress distribution after root-end surgery. Iran Endod J 2018;13:188-94.

[32] Ausiello P, Ciaramella S, Martorelli M, Lanzotti A, Gloria A, Watts DC. CAD-FE modeling and analysis of class II restorations incorporating resin-composite, glass ionomer and glass ceramic materials. Dent Mater 2017;33:1456-65.

[33] Young W, Budynas R. Stress concentrations. In: Roark's formulas for stress and strain. McGraw-Hill; 2001. Chapter 17.

[34] Gere JM, Stephen PT. Tension, ompression and shear. In: Mechanics of materials; 1984. p. 16. Chapter 1.

[35] Al Jabbari YS. Physico-mechanical properties and prosthodontic applications of $\mathrm{Co}-\mathrm{Cr}$ dental alloys: a review of the literature. J Adv Prosthodont 2014;6:138-45.

[36] Noguchi K, Michihiko F, Takaki M, Masahiro M. Tensile strength of yttria-stabilized tetragonal zirconia polycrystals. J Am Cerum Soc, 72:1305-7.

[37] Watanabe I, Watanabe E, Atsuta M, Okabe T. Tensile strength of soldered gold alloy joints. J Prosthet Dent 1997;78:260-6.

[38] Della Bona A, Benetti P, Borba M, Cecchetti D. Flexural and diametral tensile strength of composite resins. Braz Oral Res 2008;22:84-9.

[39] Abu Bakar MS, Cheng MH, Tang SM, Yu SC, Liao K, Tan CT, et al. Tensile properties, tension-tension fatigue and biological response of polyetheretherketone-hydroxyapatite composites for load-bearing orthopedic implants. Biomaterials 2003;24:2245-50.

[40] Ghahremani L, Shirkavand S, Akbari F, Sabzikari N. Tensile strength and impact strength of color modified acrylic resin reinforced with titanium dioxide nanoparticles. J Clin Exp Dent 2017;9:e661-5

[41] Nakamura K, Mouhat M, Nergård JM, Lægreid SJ, Kanno T, Milleding P, et al. Effect of cements on fracture resistance of monolithic zirconia crowns. Acta Biomater Odontol Scand 2016;2:12-9.

[42] Najeeb S, Zafar MS, Khurshid Z, Siddiqui F. Applications of polyetheretherketone (PEEK) in oral implantology and prosthodontics. J Prosthodont Res 2016;60:12-9, http://dx.doi.org/10.1016/j.jpor.2015.10.001.

[43] Gracis S, Thompson VP, Ferencz JL, Silva NR, Bonfante EA. A new classification system for all-ceramic and ceramic-like restorative materials. Int J Prosthodont 2015;28:227-35, http://dx.doi.org/10.11607/ijp.4244.

[44] Dal Piva AMO, Contreras LPC, Ribeiro FC, Anami LC, Camargo SEA, Jorge AOC, et al. Monolithic ceramics: effect of finishing techniques on surface properties, bacterial adhesion and cell viability. Oper Dent 2017;43:315-25.

[45] Rauch A, Reich S, Dalchau L, Schierz O. Clinical survival of chair-side generated monolithic lithium disilicate crowns:10-year results. Clin Oral Investig 2017;22:1763-9, http://dx.doi.org/10.1007/s00784-017-2271-3.

[46] Ozcan M, Nijhuis H, Valandro LF. Effect of various surface conditioning methods on the adhesion of dual-cure resin cement with MDP functional monomer to zirconia after thermal aging. Dent Mater J 2008;27:99-104.

[47] Monaco C, Caldari M, Scotti R. AIOP Clinical Research Group. Clinical evaluation of 1,132 zirconia-based single crowns: a retrospective cohort study from the AIOP clinical research group. Int J Prosthodont 2013;26:435-42, http://dx.doi.org/10.11607/ijp.3099.

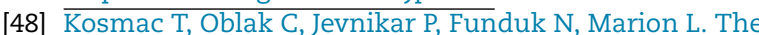
effect of surface grinding and sandblasting on flexural 
strength and reliability of Y-TZP zirconia ceramic. Dent Mater 1999;15:426-33.

[49] Fabian Fonzar R, Carrabba M, Sedda M, Ferrari M, Goracci C, Vichi A. Flexural resistance of heat-pressed and CAD-CAM lithium disilicate with different translucencies. Dent Mater 2017;33:63-70.

[50] Krejci I, Daher R. Stress distribution difference between Lava Ultimate full crowns and IPS e.max CAD full crowns on a natural tooth and on tooth-shaped implant abutments. Odontology 2017;105:254-6, http://dx.doi.org/10.1007/s10266-016-0276-z.

[51] Imanishi A, Nakamura T, Ohyama T, Nakamura T. 3-D finite element analysis of all-ceramic posterior crowns. J Oral Rehabil 2003;30:818-22.

[52] Prabhakar AR, Yavagal CM, Chakraborty A, Sugandhan S. Finite element stress analysis of stainless steel crowns. J Indian Soc Pedod Prev Dent 2015;33:183-91, http://dx.doi.org/10.4103/0970-4388.160352.

[53] Ha SR. Biomechanical three-dimensional finite element analysis of monolithic zirconia crown with different cement type. J Adv Prosthodont 2015;7:475-83, http://dx.doi.org/10.4047/jap.2015.7.6.475.

[54] Vichi A, Ferrari M, Davidson CL. Influence of ceramic and cement thickness on the masking of various types of opaque posts. J Prosthet Dent 2000;83:412-7.
[55] Uzunoğlu E, Türker SA, Yilmaz Z. Influence of cement type and thickness on polyfiber post adhesion. J Conserv Dent 2014;17:255-60, http://dx.doi.org/10.4103/0972-0707.131789.

[56] Andre CB, Aguiar TR, Ayres APA, Ambrosano GMB, Giannini $M$. Bond strength of self-adhesive resin cements to dry and moist dentin. Braz Oral Res 2013;27:389-95.

[57] Tawarczyk B, Hartmann L, Hartmann R, Roos M, Ender A, Ozcan M, et al. Impact of Gluma Desensitizer on the tensile strength of zirconia crowns bonded to dentin: an in vitro study. Clin Oral Investig 2012;16:201-13.

[58] Melo RM, Ozcan M, Barbosa SH, Galhano G, Amaral R, Bottino MA, et al. Bond strength of two resin cements on dentin using different cementation strategies. J Esthet Restor Dent 2010;22:262-8.

[59] Tannous F, Steiner M, Shahin R, Kern M. Retentive forces and fatigue resistance of thermoplastic resin clasps. Dent Mater 2012;28:273-8, http://dx.doi.org/10.1016/j.dental.2011.10.016.

[60] Jiang W, Bo H, Yongchun G, Xing NL. Stress distribution in molars restored with inlays or onlays with or without endodontic treatment: a three-dimensional finite element analysis. J Prosthet Dent 2010;103:6-12. 